\title{
Contribuições da PML e da logística ReVErsa PARA O SEgMENTo DE EMBALAGENS PLÁSTICAS: ESTUDO DE CASO EM UMA EMPRESA DO VAle do Caí (RS)
}

\author{
Gláucia Cardoso de Souza-Dal Bó ${ }^{*}$, Tiele Buchmann Postai², Amanda Bellettini Munari ${ }^{3}$
}

\author{
${ }^{1}$ Doutoranda em Ciências Ambientais pela Universidade do Extremo Sul Catarinense (PPGCA/UNESC) \\ ${ }^{2}$ Técnica em Meio Ambiente pelo Instituto Federal do Rio Grande do Sul (IFRS) \\ ${ }^{3}$ Doutoranda em Ciências Ambientais pela Universidade do Extremo Sul Catarinense (PPGCA/UNESC) \\ *Autorpara correspondência: glaudsouza@gmail.com
}

Recebido em 08 de agosto de 2016. Aceito em 30 de março de 2018. Publicado em 21 de abril de 2018.

\begin{abstract}
Resumo - As atividades industriais são responsáveis pela geração de uma série de impactos ambientais, comprometendo potencialmente a qualidade dos recursos hídricos, do solo e do meio atmosférico. No âmbito de programas de gestão ambiental, iniciativas que contemplem a Produção Mais Limpa (PML) e a logística reversa têm muito a contribuir para a melhoria da qualidade do ambiente e, paralelamente, para a redução de custos produtivos. Desse modo, diante da possibilidade de trabalhar com essa temática em uma empresa do ramo de embalagens plásticas flexíveis recicladas, situada no Vale do Caí (RS), definiu-se como objetivo: identificar e avaliar as práticas de PML e de logística reversa desenvolvidas por esse empreendimento. Por meio de um diagnóstico bastante detalhado da situação ambiental e econômica e de uma entrevista junto ao técnico ambiental, constatou-se que a empresa é bastante proativa em relação ao meio ambiente e possui iniciativas bem consolidadas de PML, incluindo a reciclagem, a recirculação de água no processo produtivo e a destinação/disposição ambientalmente adequadas dos resíduos sólidos gerados. O segmento analisado favorece vias de logística reversa, no entanto, verificou-se na prática, que as ações precisam ser mais bem articuladas no sentido de envolver um número maior de agentes dessa cadeia.
\end{abstract}

Palavras-Chave: Produção Mais Limpa; Logística Reversa; Gestão Ambiental; Plástico.

Contributions of Cleaner Production and reverse logistics for the plastic packaging segment: a case study in a Vale do Caí (RS) Company

Abstract - The industrial activities are responsible for generating a significant amount of environmental impacts, potentially compromising the quality of water resources, soil and atmosphere. In the scope of environmental management programs, initiatives that contemplate the Cleaner Production (CP) and reverse logistics can significantly contribute to the improvement of the environment quality and, at the same time, to reduce production costs. Thus, having the possibility of making a research on this theme in a flexible plastic recycled packaging company located in Vale do Caí (RS), the goal was to identify and to evaluate the $\mathrm{CP}$ and reverse logistics practices developed by this enterprise. With a help of a detailed analysis of environmental and economic situation and an interview with the environmental technician, it was verified that the company is highly proactive in relation to the environment and has well consolidated CP initiatives, including recycling, recirculation of water in the production process and the environmentally appropriate destination/disposal of generated solid wastes. The analyzed segment favors reverse logistics routes, however, it has been verified in practice that the actions need to be better articulated, involving a greater number of this network's agents.

Keywords: Cleaner Production; Reverse Logistics; Entirondental Management; Plastic. 


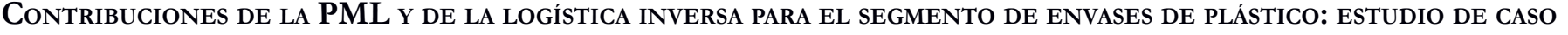 EN UNA EMPRESA DEL VALLE DEL CAÍ (RS)}

REsumen - Las actividades industriales son responsables por la generación de una serie de impactos ambientales, comprometiendo potencialmente la calidad de los recursos hídricos, del suelo y del medio atmosférico. En el ámbito de programas de gestión ambiental, iniciativas que abordan la Producción Más Limpia (PML) y la logística inversa tienen mucho que aportar para la mejoría de la calidad del ambiente y, paralelamente, para reducir los costos de producción. De ese modo, ante la posibilidad de trabajar con esta temática en una empresa del ramo de envases de plástico flexibles reciclados, ubicada en el Valle del Caí (RS), se definió como objetivo: verificar y evaluar las prácticas de PML y de logística inversa desarrolladas por este emprendimiento. Por medio de un diagnóstico muy detallado de la situación ambiental y económica y de una entrevista con el técnico de medio ambiente, se constató que la empresa es muy proactiva con relación al medio ambiente y posee iniciativas bien consolidadas de PML, incluido el reciclaje, la recirculación de agua en el proceso productivo y la distribución/eliminación ambientalmente adecuada racional de los desechos sólidos generados. El segmento analizado favorece vías de logística inversa; sin embargo, se verificó en la práctica que las acciones tienen que ser mejor articuladas en el sentido de involucrar a un mayor número de agentes de esa cadena.

Palabras clave: Producción Más Limpla; Logística Inversa; Gestión Ambiental; Plástico.

\section{INTRODUÇÃO}

As empresas e indústrias são responsáveis pela geração de uma série de impactos ambientais, dada a necessidade de manutenção dos seus processos produtivos a partir da intervenção indiscriminada sobre os sistemas ecológicos para obtenção de matérias-primas e insumos diversos. Por consequência, o ambiente é alterado, muitas vezes de forma irreversível, tendo em vista a exploração, o beneficiamento e o potencial esgotamento de muitos recursos naturais, sobretudo, não renováveis.

Barbieri (2006) esclarece que a solução para os problemas ambientais ou pelo menos, sua minimização, exige uma mudança de comportamento por parte dos empresários e administradores, os quais devem considerar o meio ambiente nas esferas administrativa e tecnológica, com a finalidade de ampliar a capacidade de suporte do Planeta. Porém, essa mudança de atitude, dificilmente, surge de forma espontânea. As preocupações ambientais por parte dos empresários decorrem usualmente de medidas governamentais coercitivas na forma de normas e leis, bem como, da pressão exercida pela sociedade enquanto clientes e compradores gradativamente mais conscientes ou sensibilizados.

Do ponto de vista da questão ambiental como uma oportunidade, a gestão ambiental pode apresentar resultados positivos: têm-se ganhos ambientais, econômicos e sociais, uma vez que são direcionados esforços para a minimização e prevenção de impactos ambientais e, concomitantemente, há uma redução de custos produtivos e um reconhecimento por parte do mercado e da sociedade de modo geral gerando uma imagem positiva do empreendimento (Montibeller-Filho 2007).

Sob a perspectiva da relação entre a empresa e o meio ambiente, podem ser adotadas posturas reativas ou proativas, na medida em que se preconizam medidas corretivas ou preventivas e se cumpre a legislação, tão somente para atender os requisitos mínimos. Uma empresa proativa é aquela que adota a prevenção da poluição ou o princípio da precaução e prevê a possibilidade de mudanças no seu processo produtivo para minimizar e, sobretudo, evitar a geração de poluição. Trata-se de uma abordagem que combina o uso sustentável dos recursos naturais e o controle da poluição. 
Nesse sentido, a Produção Mais Limpa (PML) é uma estratégia ambiental preventiva aplicada a processos, produtos e serviços com o objetivo de minimizar os impactos ambientais e reduzir os riscos para todos os seres e para o ambiente, a curto e longo prazo. Consiste em uma abordagem ambiental ampla que leva em consideração todas as fases do processo de manufatura ou do ciclo de vida do produto. $\mathrm{Na}$ sua origem, trata-se de um modelo desenvolvido pelo Programa das Nações Unidas para o Meio Ambiente PNUMA e pela Organização das Nações Unidas para o Desenvolvimento Industrial (ONUDI) desde a década de 80 (Barbieri 2006).

Após a iniciativa do PNUMA e da ONUDI, foi criado no Brasil o Centro Nacional de Tecnologias Limpas (CNTL), no Rio Grande do Sul, junto ao Serviço Nacional de Aprendizagem Industrial (SENAI); e consequentemente, no que se refere a políticas públicas, foram criados núcleos e disseminados fóruns de PML em todos os estados brasileiros com apoio do Ministério do Meio Ambiente (MMA) (Pereira e Sant'anna 2012).

Gasi e Ferreira (2006) também atribuem a concepção da PML ao PNUMA, a qual descreve uma abordagem preventiva de gestão ambiental: produzir consumindo e impactando o mínimo possível. Tal modelo sugere a melhoria contínua dos processos produtivos de modo a torná-los cada vez mais eficientes e menos depredadores do meio ambiente e da saúde humana.

Nascimento, Lemos e Mello (2008) se referem à Produção Limpa (PL), apresentada em 1989 pela organização ambientalista Greenpeace, como um sistema de produção industrial que leva em conta: o enfoque precautório, o enfoque preventivo, o controle democrático e a abordagem integrada e holística. Nesse contexto, tal proposta busca a sustentabilidade das fontes renováveis, a redução dos consumos de água e energia e a prevenção na geração de resíduos tóxicos e perigosos. Além disso, se atém à reutilização e ao reaproveitamento de materiais por reciclagem de maneira atóxica e eficiente em termos energéticos e à geração de produtos duráveis.

No âmbito da PML, a logística reversa também pode ser citada, enquanto uma ferramenta introduzida pela Política Nacional dos Resíduos Sólidos (Brasil 2010), que lança a ideia da responsabilidade compartilhada pelo ciclo de vida dos produtos. Na verdade, quando se fala em avaliação de ciclo de vida ou mesmo em PML, se fala em logística reversa, tendo em vista as contribuições que tais modelos ou instrumentos promovem para a melhoria da qualidade ambiental e da qualidade de vida.

Segundo a legislação supracitada, logística reversa é um instrumento de desenvolvimento econômico e social caracterizado por um conjunto de ações, procedimentos e meios capazes de viabilizar a coleta e a restituição dos resíduos sólidos ao setor empresarial, para que este proceda com o reaproveitamento em seu ciclo produtivo ou em outros.

Costa, Mendonça e Souza (2014) diferem a logística tradicional empregada pelas organizações, dita direta, da logística reversa. A logística direta tem como premissa o aumento da velocidade de resposta e de serviço aos clientes, por meio da velocidade do fluxo logístico e da redução dos custos totais de operação. Em contrapartida, a logística reversa opera no sentido contrário, na medida em que garante o retorno dos produtos, materiais e peças a um novo processo ou novo uso.

Esse instrumento tem como objetivo, em linhas gerais, recuperar o valor ou salvaguardar que o descarte ocorra de forma ambientalmente adequada. Entretanto, a viabilização de um processo no sentido inverso ao tradicional para o empreendedor, torna-se atrativo e consequentemente exequível, quando é eficiente e de baixo custo.

Xavier e Côrrea (2013) esclarecem que os fluxos reversos caminham contra a corrente dos fluxos diretos, da ponta do consumo para trás. Tal processo é concebido quando materiais e componentes de produtos ou 
de processos, depois de serem consumidos ou utilizados, são coletados e transportados para trás nas redes e suprimentos, para que sejam reutilizados ou reciclados. Esses resíduos podem ser reincorporados na mesma cadeia de suprimentos ou em outras cadeias.

Diferentemente de Costa, Mendonça e Souza (2014), Xavier e Côrrea (2013) se referem a esses sistemas como redes de suprimentos de ciclo fechado, como aquelas compostas por fluxos diretos e reversos, formando ciclos de materiais que retornam a pontos anteriores da rede para reutilização ou reprocessamento para nova utilização.

Desse modo, o setor industrial se defronta com um problema que tem sua gênese na redução da vida útil de um determinado produto e na necessidade de descartá-lo. Consequentemente, tem-se o aumento da geração de resíduos, a necessidade constante de novos locais de disposição e a busca por alternativas técnicas de tratamento, viáveis ambiental e economicamente (Piva e Weibeck 2004). É nesse sentido que a PML e a logística reversa podem contribuir enquanto instrumentos de gestão, para a melhoria da qualidade ambiental e social, bem como, para a redução de custos no âmbito produtivo.

Diante da diversidade de segmentos produtivos existentes, a indústria do plástico, notadamente, contribui para a geração uma série de impactos ambientais adversos, seja nas etapas pré ou pós-consumo, já que a principal matéria-prima da qual se origina é o petróleo e ao final da sua vida útil, o plástico permanece no ambiente por um longo período.

Conforme dados da Pesquisa Industrial Anual (PIA - Empresa), há um total de 325,28 mil indústrias no país: 318,23 mil de transformação e 7,05 mil extrativas. O segmento ligado à fabricação de plástico para embalagens está representado por uma produção nacional de cerca de 1,3 milhões de ton./ano. O estado Rio Grande do Sul contribui com a fabricação de 38,72 mil ton./ano de produtos nesse segmento (Ibge 2017).

Destaca-se que a fabricação de material plástico, no cenário da contribuição econômica da indústria de transformação, é um dos segmentos econômicos característicos do Vale do Caí (RS), em conjunto com a produção de alimentos, de máquinas e equipamentos e com a produção de móveis, vidro e cimento (Corede 2015). Segundo dados da Fundação de Economia e Estatística (FEE), os produtos de borracha e de material plástico representam 4,3\% das atividades econômicas desenvolvidas no estado gaúcho (Rio Grande do Sul 2017).

A fabricação de embalagens de material plástico, comparativamente com os outros tipos de materiais também destinados à produção de embalagens - papel, madeira, vidro e metálicos - possui o maior percentual de participação, com 35\% no ano de 2014, no segmento da indústria de embalagens nacional (Abre 2014). Nesse sentido, uma das alternativas, face à crescente produção de materiais plásticos, é estimular a prática de reciclagem desse material, cujo índice de reciclagem nacional é de 22\% (Abiplast 2012); e possivelmente, inseri-lo na rota da logística reversa de uma região ou segmento produtivo.

Diante do exposto, questiona-se: quais práticas de PML poderiam ser desenvolvidas por uma empresa do segmento de embalagens plásticas? De que modo a logística reversa pode ser implementada nesse segmento? Quais as dificuldades inerentes à gestão ambiental em uma empresa de embalagens plásticas? É possível fabricálas usando matéria-prima reciclada mantendo a mesma qualidade de embalagens produzidas a partir de matériasprimas virgens? Quais os impactos ambientais mais significativos atrelados ao segmento em análise?

Para elucidar tais questionamentos, o presente estudo foi conduzido sob a perspectiva exploratória, na forma de estudo de caso em uma empresa de embalagens flexíveis recicladas situada no Vale do Caí, estado 
do Rio Grande do Sul, a partir de uma abordagem qualitativa dos dados, que foram coletados e sistematizados entre 2014 e 2015. Em linhas gerais, buscou-se identificar e avaliar as práticas de PML e logística reversa desenvolvidas pela empresa-alvo do estudo de caso, enquadrada no segmento de embalagens plásticas recicladas, por meio de uma análise do seu processo produtivo e de um diagnóstico da situação econômico-ambiental do empreendimento.

\section{MATERIAL E MÉTODOS}

\section{Caracterização do local de estudo}

A pesquisa foi desenvolvida a partir da realidade experenciada por uma empresa produtora de embalagens plásticas flexíveis recicladas, localizada no Vale do Caí (RS) (Figura 1). O empreendimento está inserido em uma região com três grandes centros (Montenegro, São Sebastião do Caí e Salvador do Sul) e situa-se bastante próxima das regiões metropolitanas de Porto Alegre.

Figura 1 - Localização da região do Vale do Caí, estado do Rio Grande do Sul.

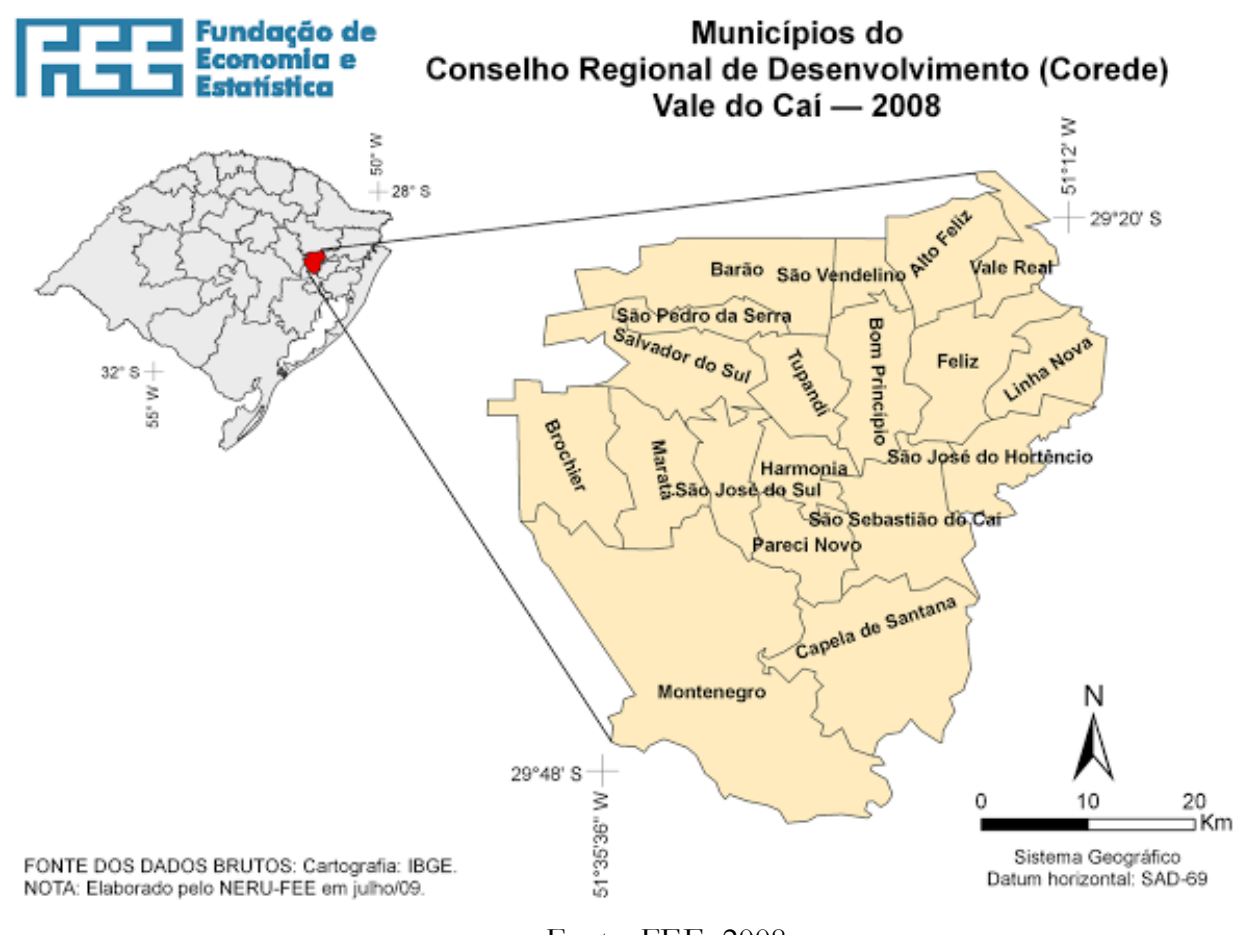

Fonte: FEE, 2008.

A empresa analisada fabrica embalagens plásticas flexíveis a partir de matéria-prima virgem e, principalmente, secundária. A produção anual para 2013 foi estimada em 400 mil toneladas (ton.). de plástico, 50 mil bobinas e 325 mil unidades de sacos plásticos. Os maiores fornecedores de matéria-prima situam-se nos estados do Rio Grande do Sul, Santa Catarina e São Paulo; e os principais compradores pertencem ao ramo moveleiro, alimentício e de bebidas, localizados no estado do Rio Grande do Sul, sobretudo, nos municípios de Lajeado, Tupandi, Bento Gonçalves e Porto Alegre. 


\section{Caracterização da pesquisa}

De acordo com o objetivo delineado, trata-se de uma pesquisa qualitativa, do tipo exploratório. A pesquisa qualitativa é essencialmente interpretativa e inclui, para tanto, o desenvolvimento da descrição de uma pessoa ou cenário, a análise de dados para identificar temas ou categorias e, por fim, tirar conclusões sobre seu significado a partir da interpretação (Creswell 2007). O objetivo principal é o aprimoramento de ideias ou a descoberta de intuições. Na maioria dos casos, envolvem levantamento bibliográfico, entrevistas e análise de exemplos. Por consequência, é comum assumir o método de estudo de caso (Gil 2007).

O estudo de caso caracteriza-se pela coleta e registro de dados de um caso em particular, ou de vários casos com a finalidade de organizar um relatório ordenador e crítico de uma experiência, com o propósito último de tomada de decisão ou de proposição de uma ação transformadora. É um estudo exaustivo, de vários ou de um único objeto, levando em conta que a análise de uma unidade de determinado universo permite a compreensão da sua generalidade ou a identificação de bases creditáveis para nortear uma investigação futura (Chizzotti 1991; Gil 2007).

\section{Coleta de dados}

Os dados disponibilizados pela empresa em análise foram coletados e sistematizados entre os anos de 2014 e 2015. A pesquisa foi dividida em três etapas, conduzidas consecutivamente:

$1^{\text {a }}$ etapa - Visita técnica à empresa para o acompanhamento do processo produtivo em conjunto com os responsáveis pelas áreas de meio ambiente e de produção, com o propósito de identificar as matérias-primas utilizadas, os impactos gerados e as formas de destinação e/ou disposição adotadas. Todas as etapas foram observadas, desde o recebimento das matérias-primas até a expedição do produto final.

$2^{\mathrm{a}}$ etapa - Consulta a documentos que subsidiaram a quantificação dos impactos gerados, bem como, das despesas e receitas derivadas do processo produtivo, quais sejam, faturas, relatórios, laudos, licenças, registros de monitoramento e afins. Essa diversidade de dados e informações, aliada ao conhecimento detalhado do processo produtivo, permitiu conferir um diagnóstico das práticas de PML e de logística reversa. As práticas foram classificadas em relação aos dois grandes eixos e aos níveis da PML, conforme ilustra a Figura 2.

$\mathbf{3}^{\mathbf{a}}$ etapa - Elaboração de uma entrevista semi-estruturada, que consiste em um conjunto de questões predefinidas e tem por finalidade, conferir mais liberdade ao pesquisador para que sejam exploradas outras questões que por ventura surjam no decorrer da entrevista. Tal instrumento foi aplicado junto ao responsável técnico pela área ambiental e ao proprietário da empresa, atentando para a logística reversa, suas perspectivas e limitações. Os sujeitos de pesquisa foram escolhidos em função de serem os maiores conhecedores do funcionamento do processo produtivo e das questões ambientais na empresa. Tentou-se a partir desse instrumento, identificar a entropia do sistema de logística reversa da empresa analisada, com base no exposto por Costa, Mendonça e Souza (2014), na Figura 3. 
Figura 2 - Níveis de intervenção da PML.

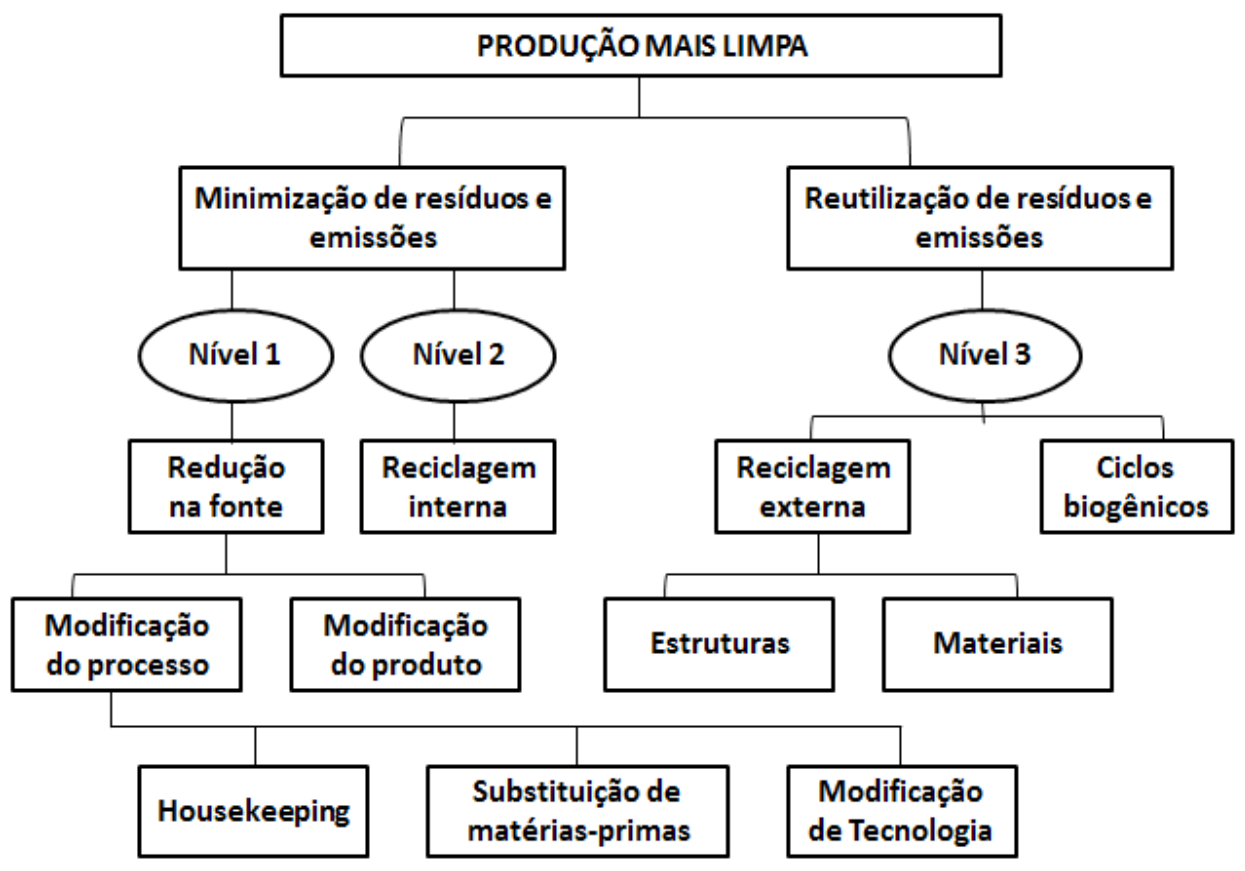

Fonte: Barbieri 2006, p. 122.

Figura 3 - Entropia nos sistemas de logística direta e reversa.

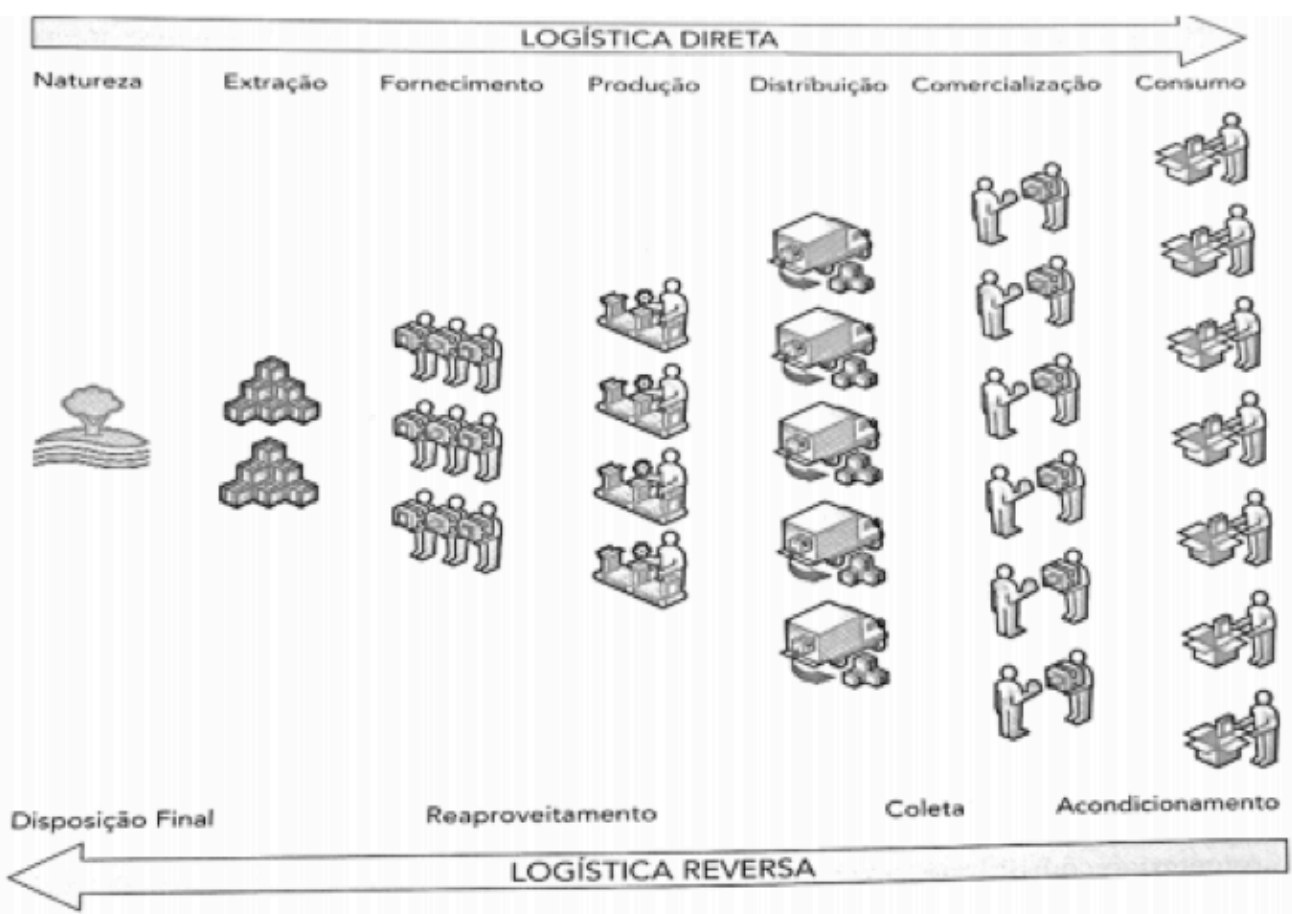

Fonte: Costa; Mendonça; Souza 2014, p. 20.

\section{REsultados E Discussão}

Análise ambiental do processo e identificação das práticas de PML

A empresa analisada fabrica seus produtos tanto a partir de matérias-primas virgens (polietileno), quanto 
secundárias. Destaca-se, entretanto, que sua atuação no mercado está bem mais voltada para o uso de plástico reciclado, a partir de polímeros secundários, do que dependente de matéria-prima virgem. Trata-se de um processo bastante automatizado e de ciclo ininterrupto, que demanda grande consumo energético.

Quando a matéria-prima secundária (plásticos diversos) é recebida, ela é inicialmente pesada, vistoriada e estocada. Após passar pela esteira de segregação, os diversos tipos de plástico passam pelas etapas de classificação e lavagem. A classificação é feita de acordo com a cor e com a qualidade do plástico recebido, usualmente, em canela (plástico mais escuro), stretch (plástico filme, mais maleável) ou barulhento (não é utilizado por deixar falhas no produto final).

O material selecionado é moído ou triturado, seguindo para a conformação em pellets -grânulos formados a partir de resinas poliméricas processadas pela indústria química. O material resultante é aquecido e o seu amolecimento confere a ele o formato desejado. Em seguida, ele é resfriado bruscamente, para que endureça com o choque térmico. Novamente o material é aquecido e através de um sopro de ar, forma-se uma bolha plástica que dá origem ao filme de plástico. Então, o material é prensado ao passar pelos rolos e é encaminhado para as bobinas. O produto passa ainda pela impressora, cuja coloração necessita de pigmentos, segue para o controle de qualidade e, finalmente, segue para a expedição.

Compreendendo que cada etapa está atrelada ao consumo e externalização negativa de um ou mais impactos ambientais, identificaram-se os imputs e outputs, para proceder com a análise de todos os impactos gerados por esse processo. Entende-se por externalidades negativas, todas as formas de poluição e consequente degradação ambiental, cujos custos econômicos e sociais não são contabilizados pelo sistema econômico vigente (Cavalcanti 2003; Cavalcanti 2004). A Figura 4 ilustra as entradas e saídas, bem como, as etapas que compõem o processo produtivo de fabricação do plástico.

Figura 4 - Descrição dos inputs, outputs e das etapas do processo produtivo.

\begin{tabular}{|c|}
\hline Inputs \\
\hline Água \\
Energia \\
MP virgem \\
MP secundária \\
Pigmentos \\
Transporte \\
\hline
\end{tabular}

\begin{tabular}{|c|}
\hline Processos \\
\hline Recebimento MP \\
Armazenamento MP \\
Classificação \\
Lavagem e secagem \\
Extrusora recuperadora \\
Extrusora de filmes \\
Boleadeira \\
Impressora \\
Estoque \\
\hline
\end{tabular}

\begin{tabular}{|c|}
\hline Outputs \\
\hline Produto \\
Efluentes \\
Residuos \\
Rejeito (lodo) \\
Emissões \\
Material particul. \\
Ruídos \\
\hline
\end{tabular}

A matéria-prima secundária, ou seja, o plástico que é encaminhado à empresa pelos fornecedores, geralmente, vem embalado com papel/papelão ou misturado a outros tipos de plástico, como garrafas de Polietileno Tereftalato (PET). Todo esse material é acumulado separadamente e comercializado com recicladores locais. O mesmo ocorre com o plástico que não passa pela etapa de classificação e não pode ser utilizado no processo por comprometer a qualidade do produto final. Também são gerados, ainda que de forma pouco expressiva, resíduos de varrição, a partir da limpeza do pátio e arredores. Esses resíduos são encaminhados para disposição em aterro. 
A água utilizada pela empresa, principalmente, na etapa de lavagem, provém de um poço de propriedade própria e obedece a um sistema de recirculação. Quando o efluente já se encontra bastante poluído, ele é tratado dentro da própria empresa, em uma estação de tratamento (ETE). A princípio, o lodo era tratado como rejeito e enviado para disposição em aterro industrial. Atualmente, é considerado um resíduo, cuja forma de destinação é o uso em solo agrícola, depois de pesquisas que viabilizaram tecnicamente essa alternativa de destinação.

Adverte-se ainda, que há a geração de um resíduo denominado "farinha de plástico", originado nas etapas de lavagem e trituração. Quando o plástico passa pelas bobinas, há também o descarte de aparas plásticas. Ambos os resíduos são utilizados novamente, ou seja, introduzidos no processo produtivo. O Quadro 1 ilustra as principais externalidades do processo, a etapa na qual são geradas e as formas de destinação/disposição usuais.

Quadro 1 - Principais impactos e formas de disposição/destinação adotadas.

\begin{tabular}{|l|l|l|}
\hline \multicolumn{1}{|c|}{ Item } & \multicolumn{1}{|c|}{ Etapa Proveniente } & \multicolumn{1}{c|}{$\begin{array}{c}\text { Formas de destinação/ } \\
\text { disposição }\end{array}$} \\
\hline Farinha de plástico & Lavagem e trituração & Reinserção no processo \\
\hline Aparas plásticas & Fabricação em bobinas & Reinserção no processo \\
\hline Resíduos de varrição & Pátio externo e interno & Aterro \\
\hline Papel/papelão e de plástico & Armazenamento/processo & Comércio de recicláveis \\
\hline Efluente & Lavagem & Recirculação/Tratamento \\
\hline Lodo de ETE & Segregação e ETE & Aplicação em solo agrícola \\
\hline
\end{tabular}

Analisando os níveis e a hierarquia de intervenção da PML (Figura 2), a empresa analisada desenvolve práticas enquadradas nas duas vertentes principais: (1) minimização e (2) reutilização de resíduos e emissões. Ela também desenvolve ações em conformidade com os três níveis: nível 1 (redução na fonte), nível 2 (reciclagem interna) e nível 3 (reciclagem externa). O Quadro 2 caracteriza as práticas de PML, em relação aos níveis de atuação, desenvolvidas pela empresa em análise.

Quadro 2 - Classificação das práticas de PML em função dos níveis de atuação.

\begin{tabular}{|l|c|c|c|}
\hline \multicolumn{1}{|c|}{ Vertente } & \multicolumn{2}{c|}{ Minimização } & Reutilização \\
\hline \multicolumn{1}{|c|}{ Nível } & Nível 1 Redução & Nível 2 Reci. interna & Nível 3 Reci. externa \\
\hline Consumo de matéria-prima secundária & $\mathrm{X}$ & & $\mathrm{X}$ \\
\hline Geração de farinha de plástico & & $\mathrm{X}$ & \\
\hline Geração de aparas plásticas & & $\mathrm{X}$ & $\mathrm{X}$ \\
\hline Geração de resíduos recicláveis* & & & $\mathrm{X}$ \\
\hline Geração de efluente & $\mathrm{X}$ & & \\
\hline Geração de lodo de ETE & & & \\
\hline
\end{tabular}

*papel/papelão e plástico.

O emprego de polímeros secundários no processo produtivo implica em uma redução no consumo de matéria-prima virgem, usualmente, à base de recursos não renováveis. É possível, portanto, reduzir na fonte o uso desse insumo. Destaca-se ainda, que a empresa analisada faz reciclagem externa em relação a essa matériaprima, já que insere no seu processo um resíduo descartado por outra indústria ou fonte geradora. Logicamente, o processo e o produto foram modificados, com a gradativa substituição da matéria-prima virgem pela secundária, 
sem prejuízos para o produto final.

Do mesmo modo, o reuso da água na etapa de lavagem e na estação de tratamento permite uma redução considerável no consumo desse recurso. Outra forma de reciclagem externa é representada pelo lodo gerado na ETE, utilizado em solo agrícola, sem causar danos para suas funções biológicas.

A reciclagem interna é feita quando a farinha e as aparas de plásticos são novamente inseridas no processo. E a reciclagem externa caracteriza-se pela comercialização de papel/papelão e plástico impróprio para o processo, junto aos recicladores locais.

Análise econômica: redução de custos produtivos a partir da PML

Tendo em vista os principais insumos produtivos que fazem parte desse processo, a empresa analisada tem um custo anual na ordem de aproximadamente $\mathrm{R} \$ 6,9$ milhões, admitindo que a maior parte desse montante se refere às matérias-primas virgem e secundária, as quais totalizam 1.150,11 ton./ano e um custo de 4.125.883 R\$ /ano. A Tabela 1, elaborada a partir dos dados fornecidos pela empresa-alvo do estudo de caso, apresenta um detalhamento dos quantitativos em relação aos seus principais insumos e custos.

Tabela 1 - Quantidade anual estimada das principais matérias-primas usadas no processo de fabricação de embalagens plásticas em função dos custos.

\begin{tabular}{lccc}
\hline \multicolumn{1}{c}{ Matéria-prima } & Quantidade (ano) & R\$/ano & \% (custo) \\
\hline Matéria-prima secundária & $1.149,749$ ton. & 1.954 .183 & 28,4 \\
Polietileno (MP virgem) & $0,361 \mathrm{ton}$. & 2.171 .700 & 31,6 \\
Água & $22.000 \mathrm{~m}^{3}$ & $*$ & 0 \\
Energia & $11.011 .160 \mathrm{~kW} / \mathrm{h}$ & 2.752 .790 & 40 \\
\hline Total & & $\mathbf{6 . 8 7 8 . 6 7 3}$ & $\mathbf{1 0 0}$ \\
\hline
\end{tabular}

*Não há custo com o consumo de água, pois a empresa possui um poço de sua propriedade.

O consumo de energia representa o maior custo que a empresa possui com os insumos para a fabricação de embalagens plásticas. Além dos custos com esses insumos, há àqueles decorrentes do tratamento dos resíduos e efluentes gerados no processo, os quais somam R $\$ 142.700 /$ ano.

Destaca-se, com base nos dados da Tabela 2, que a operação da estação de tratamento é bastante onerosa para o empreendimento: são, em média, $19.000 \mathrm{~m}^{3}$ de efluentes tratados anualmente e um custo de $\mathrm{R} \$ 130.000$ / ano. A empresa também arca com a disposição de 141 ton./ano de resíduos de varrição em aterro, a partir de um custo de $\mathrm{R} \$ 12.700 /$ ano.

Quando o lodo gerado pela ETE era encaminhado para um aterro industrial, a empresa desembolsava R \$ 60.000/ano para dispor cerca de 598 ton./ano de lodo. Atualmente, não há custo algum com esse resíduo, assim como também não há custo com a destinação ou disposição da farinha e das aparas de plástico (Tabela 2).

Considerando todos os tipos de resíduos gerados pelo empreendimento, com exceção da farinha e das aparas de plástico que são internamente recicladas no processo, tem-se um total de 141 ton./ano ou 11,75 ton./ mês. Em contrapartida, é importante salientar que a empresa de embalagens plásticas consegue reduzir seus custos em R $\$ 28 \mathrm{mil} /$ ano ou $\mathrm{R} \$ 2,33 \mathrm{mil} / \mathrm{mês}$ com a comercialização de 93,8 ton. recicláveis (papel, papelão e plástico). 
Tabela 2 - Quantidade anual estimada dos principais impactos gerados, relacionada com os custos e com a destinação e/ ou disposição adotadas.

\begin{tabular}{lccc}
\hline \multicolumn{1}{c}{ Prática } & $\begin{array}{c}\text { Quantidade } \\
(\mathbf{a n o})\end{array}$ & $\begin{array}{c}\text { Destinação } \\
\text { Disposição }\end{array}$ & R\$/ano \\
\hline${ }^{1}$ Comercialização de papel/papelão & 75,02 ton. & Reciclagem externa & 18.700 \\
${ }^{2}$ Comercialização de plástico & 18,78 ton. & Reciclagem externa & 9.300 \\
${ }^{3}$ Geração de efluentes & $19.000 \mathrm{~m}^{2}$ & Tratamento ETE & 130.000 \\
${ }^{4}$ Geração de lodo ETE & 598 ton. & Solo agrícola & $* *$ \\
${ }^{5}$ Geração de resíduos de varrição & 141 ton. & Aterro & 12.700 \\
${ }^{6}$ Geração de farinha de plástico & $*$ & Reciclagem interna & $* *$ \\
${ }^{7}$ Geração de aparas de plástico & $*$ & Reciclagem interna & $* *$ \\
Total & RECEITAS $^{1,2}$ & & $\mathbf{2 8 . 0 0 0}$ \\
& DESPESAS $^{3,5}$ & & $\mathbf{1 4 2 . 7 0 0}$ \\
\hline
\end{tabular}

*Não há estimativa de geração.

**Não há custo.

Totalizando os custos com os insumos, com o tratamento de efluentes e com a disposição dos resíduos de varrição, a empresa possui uma despesa de $\mathrm{R} \$ 7.021 .373 /$ ano ou $\mathrm{R} \$ 585.114,41 /$ mês. Por outro lado, descontando a receita gerada com a comercialização de recicláveis, esse custo cai para $\mathrm{R} \$$ 6.993.373/ano ou $\mathrm{R} \$ 582.781,08 /$ mês. Portanto, além da não geração e da minimização considerável de impactos ambientais, a empresa consegue obter benefícios econômicos com a implementação da PML, sobretudo, a partir da reciclagem interna e externa ao seu processo produtivo.

\section{Logística reversa: vantagens e limitações para o segmento de embalagens plásticas}

Depois que as embalagens plásticas são fabricadas e expedidas, elas podem percorrer dois caminhos em função dos clientes potenciais, ditos, diretos e indiretos. Geralmente, as embalagens são utilizadas para acondicionar produtos da empresa de alimentos e de bebidas, além de embalarem móveis e seus acessórios.

As embalagens chegam nessas indústrias, que são clientes indiretos, e podem ser comercializadas com outras empresas ou revendedores (ainda indiretos), até chegar aos clientes finais (diretos). Os clientes finais são supermercados, lanchonetes, bares e afins, além de lojas de móveis, que compram seus produtos enfardados para revendê-los aos consumidores comuns, pessoas físicas.

Portanto, as embalagens plásticas podem ser descartadas pelos diversos agentes que fazem parte dessa cadeia e, igualmente, serem destinadas de diferentes formas. Quando não se tem segregação na fonte geradora, as embalagens seguem para locais de disposição final. Quando há segregação, todavia, essas embalagens plásticas podem ser reaproveitadas ou recicladas, no mesmo ou em outros processos produtivos. A Figura 6 ilustra a entropia da logística direta e reversa da empresa de embalagens plásticas.

Em suma, quando as embalagens plásticas não cumprem mais a sua função de acondicionar os produtos acima descritos, podem ser reaproveitadas, enviadas para a reciclagem ou ainda, encaminhadas para vias de disposição final misturadas com outros resíduos. Sob tal ótica e compreendendo o que são externalidades negativas, é relevante ressaltar a importância de internalizá-las, de modo que não permaneçam invisíveis ao 
mercado e que contabilizando tais custos, tanto sociais, quanto ambientais, tenhamos um redirecionamento da racionalidade produtiva; a qual leve em consideração princípios da sustentabilidade ecológica, da equidade social e da diversidade cultural (Leff 2011).

Figura 5 - Entropia do sistema de logística direta e reversa da empresa plástica em estudo.

Logística direta

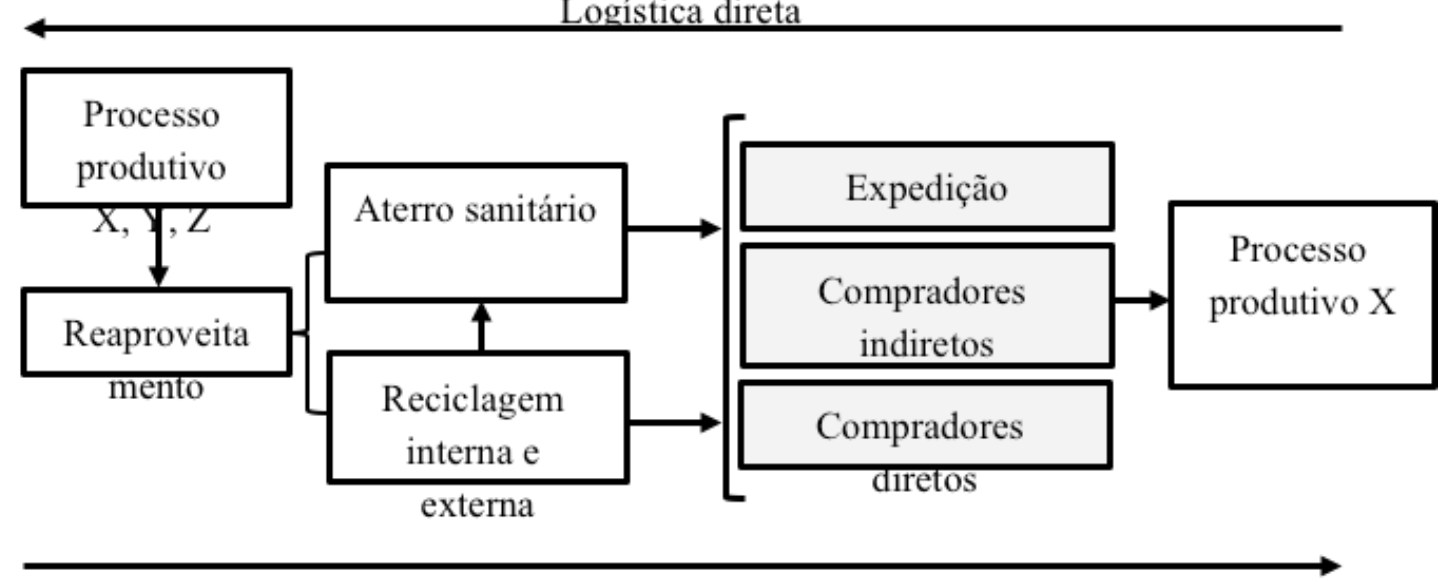

Logística reversa

No que diz respeito às limitações apontadas pelo técnico em meio ambiente em relação à logística reversa nesse segmento, ele se refere prontamente aos custos atrelados à reciclagem no Brasil. Os impostos são mais elevados, segundo ele, para o segmento que faz uso de matéria-prima reciclada, comparativamente àquela que emprega matéria-prima virgem. Logo, não há nenhum favorecimento econômico, por parte do poder público, às indústrias que se mantém sem explorar recursos naturais, sejam eles renováveis ou não renováveis.

A ausência de matéria-prima secundária de qualidade também foi mencionada como um grande problema para esse segmento, sobretudo, na região onde se insere. Não há um fornecimento estável de plástico para esse processo, tanto é que a empresa em análise importa matéria-prima secundária de outros estados. Portanto, a manutenção de canais reversos desse sistema é dificultada pela falta de interesse, tanto dos empreendedores, quanto dos clientes, no momento pós-consumo do plástico.

Os custos adicionais com a implementação, gestão, execução e manutenção de um sistema devidamente planejado e articulado de logística reversa não estão computados pelos empreendedores, que os enxergam, inevitavelmente, como despesas e não como investimentos. De acordo com os entrevistados, é preciso investir, sobretudo, em recursos humanos e operacionais destinados à coleta e transporte desse material.

Sobre as perspectivas relativas à logística reversa, os entrevistados acreditam que seu uso dificilmente será disseminado, caso não se tenha uma articulação mais clara e coesa das ações a serem desenvolvidas por todos os agentes integrantes da cadeia. Comentou-se ainda, que a Política Nacional de Resíduos Sólidos apresenta a logística reversa como um instrumento, entretanto, não há traz como uma ferramenta obrigatória, tampouco aponta diretrizes para sua execução.

Quanto aos benefícios da logística reversa, a melhoria da imagem corporativa foi mencionada como principal vantagem, sobretudo, diante dos clientes, que buscam produtos ecologicamente corretos, e até mesmo dos fornecedores. Sob a ótica dos profissionais entrevistados, os impactos ambientais mais expressivos que podem ser minorados ou evitados, os quais justificam a adoção de um sistema de logística reversa, compreendem a redução do envio de materiais plásticos para aterros sanitários, bem como, a redução nos consumos energético 
e hídrico, que são consideravelmente elevados no segmento que usa matéria-prima exclusivamente virgem.

\section{CoNSIDERAÇÕES FINAIS}

Constatou-se que a empresa analisada possui práticas bem consolidadas de PML, bem como, se insere na perspectiva da logística reversa. Tendo em vista que as premissas básicas da PML são a reciclagem interna e externa ao processo produtivo, observou-se que muitos dos resíduos sólidos gerados podem ser reincorporados ao processo produtivo, enquanto outros são comercializados com recicladores; e aqueles, cujas características não permitem a reciclagem são dispostos adequadamente.

O consumo de energia revelou-se como o impacto mais significativo, exigindo ações de manutenção preventiva nos maquinários e de boas práticas por parte do todos os funcionários. A empresa consegue ainda, recircular água no processo, evitando um consumo mais elevado desse recurso. O lodo gerado pela ETE não representa mais um custo para o empreendimento, já que foi possível dispô-lo em solo agrícola.

De acordo com o técnico ambiental da empresa, não são percebidas formas de favorecimento ou de compensação econômica às empresas que deixam de extrair recursos naturais do ambiente e que promovem processos produtivos mais sustentáveis. Logo, é preciso envolver os governos por meio de incentivos para as empresas praticantes da logística reversa e da PML. Uma das dificuldades citadas foi a ausência de matéria-prima secundária de qualidade e a necessidade de busca-la em outros estados. Se houvesse uma conscientização quanto ao descarte desse material, ele poderia ser encontrado mais próximo ao comprador.

Talvez pelo fato da não houver uma obrigatoriedade legal em relação ao uso da logística reversa como um instrumento de gestão ambiental, não há efetivamente um interesse por parte dos empreendedores na sua viabilização. Práticas consistentes nesse sentido carecem de um envolvimento e de um comprometimento de um número maior de agentes, incluindo consumidores a partir de um descarte consciente, dos órgãos ambientais com a fiscalização e dos empreendedores, através de investimentos em recursos humanos e operacionais para a consolidação no uso desse instrumento.

Os benefícios da PML e da logística reversa são facilmente perceptíveis e possíveis de serem alcançados. A partir de pequenas ações, que muitas vezes não requerem alta tecnologia ou investimentos financeiros de grande monta, a empresa consegue reduzir custos, minimizar a ocorrência de impactos ambientais e ainda, melhorar a sua imagem junto ao público consumidor.

\section{REFERÊNCIAS}

ABRE - Associação Brasileira de Embalagem. Estudo macroeconômico da embalagem. 2014. Disponível em: $<$ http://www.abre.org.br/setor/dados-de-mercado/>. Acesso em: jan. 2018.

ABIPLAST - Associação Brasileira da Indústria de Plástico. 2012. Disponível em: $<$ http://www.mdic.gov.br/ arquivos/dwnl_1395062729.pdf>. Acesso em: jan. 2018.

Barbieri JC. 2006. Gestão ambiental empresarial: conceitos, modelos e instrumentos. São Paulo: Saraiva, 328 p. 
Brasil. Política Nacional de Resíduos Sólidos. 2010, 72 p.

Cavalcanti C. 2003. Meio ambiente, Celso Furtado e o Desenvolvimento como Falácia. Ambiente \& Sociedade, (5): 73-84.

Cavalcanti C. 2004. Uma tentativa de caracterização da economia ecológica. Ambiente \& Sociedade. (7): 149156.

Chizzotti A. 1991. Pesquisa em ciências humanas e sociais. 3. ed. São Paulo: Ed. Cortez, 164 p.

Costa L e Mendonça FM de. 2014. Logística Reversa segundo a Visão de Processos. In: VALLE, R; SOUZA, R. G. de (Org.). Logística reversa: processo a processo, 3, São Paulo: Atlas, p. 34-48.

COREDE. 2015. Perfil Socioeconômico. COREDE. Disponível em: < http://planejamento.rs.gov.br/upload/ arquivos/201512/15134136-20151117104014perfis-regionais-2015-vale-do-cai.pdf>. Acesso em ago. 2016.

Creswell J. W. 2007. Projeto de pesquisa: métodos qualitativo, quantitativo e misto. 2. ed. Porto Alegre: Artmed. $248 \mathrm{p}$.

FEE. 2008. Fundação de Economia e Estatística Siegfried Emanuel Heuser - FEE. Municípios do Conselho Regional de Desenvolvimento (Corede) Vale do Caí. Porto Alegre. Disponível em: < $\underline{\text { http://mapas.fee.tche.br/ }}$ wp-content/uploads/2009/08/corede vale do cai 2008 municipios.png >. Acesso em: abr. 2016.

Gasi TMT e Ferreira E. 2006. Produção Mais Limpa. In VILELA JÚNIOR, A; DEMAJOROVIC, J (Org.). Modelos e ferramentas de gestão ambiental: desafios e perspectivas para as organizações, 2, São Paulo: SENAC/SP, p. 45-82.

Gil AC. 1994. Metodologia do ensino superior. 2 ed. São Paulo: Ed. Atlas, 207 p.

Gil AC. 2007. Como elaborar projetos de pesquisa. 4. ed. São Paulo: Atlas.

IBGE - Instituto Brasileiro de Geografia e Estatística. Brasil em números. v. 25, 2017. Disponível em: $<\underline{\text { https: } / /}$ biblioteca.ibge.gov.br/visualizacao/periodicos/2/bn_2017_v25.pdf>. Acesso em: jan 2018.

IBGE - Instituto Brasileiro de Geografia e Estatística. Brasil em números. Pesquisa Industrial Anual: Empresa - PIA Empresa. 2017. Disponível em: $<$ https://www.ibge.gov.br/estatisticas-novoportal/economicas/ industria/9042-pesquisa-industrial-anual.html?\&t=series-historicas $>$. Acesso em: jan 2018.

Leff E. 2001. Economia ecológica e ecologia produtiva. In: LEFF, E. Saber ambiental: sustentabilidade, racionalidade, complexidade e poder, 3, Petrópolis, RJ: Vozes, p. 42-55.

Montibeller-Filho G. 2007. Empresas, desenvolvimento e ambiente: diagnóstico e diretrizes de sustentabilidade. Barueri, SP: Manole, 147 p.

Nascimento LF; Lemos AD da C e MELLO MCA de. 2008. Gestão socioambiental estratégica. Porto Alegre: Bookman, 229 p. 
Pereira GR; Sant'Anna FSP. 2012. Uma análise da produção mais limpa no Brasil. Revista Brasileira de Ciências Ambientais. (24): 17-26.

Piva AM; Wiebeck H. 2004. Reciclagem do plástico. Como fazer da reciclagem um negócio lucrativo. São Paulo: Artliber Editora. 119 p.

Rio Grande do Sul em números: 2017 - coordenação de Tomás Amaral Torezani. - Porto Alegre: FEE, 2017. 48 p.

XavierLH e Corrêa HL. 2013. Sistemas de logística reversa: criando cadeias de suprimento sustentáveis. São Paulo: Atlas, 265 p. 